\title{
Metalurgia medieval aplicada a la construcción. Las rejas góticas de la Catedral de Barcelona
}

\section{Medieval metallurgy applied to construction. The gothic bars of Barcelona Cathedral}

\author{
Jordi Auladell Marquès \\ Facultat d'Humanitats. Universitat Internacional de Catalunya \\ e-mail: jauladell@uic.es
}

Júlia Simon Arias $(\dagger)$

Dept. Ciència dels Materials i Enginyeria Metal·lúrgica. E.T.S.E.I.B. Universitat Politècnica de Catalunya

\begin{abstract}
RESUMEN
En la Catedral de Barcelona se mantienen en uso diversas rejas contemporáneas a la construcción gótica original, elaboradas con estructura de hierro o acero y apliques decorativos de aleación de cobre. Previas a los avances en calidad y productividad de las innovaciones del método catalán del s. XVII, se ha considerado de interés identificar el nivel tecnológico aplicado mediante su estudio metalográfico. El análisis ha consistido en la obtención de muestras para su observación en microscopía óptica y electrónica (SEM), microdurometría y microanálisis (EDAX). De forma genérica, los resultados evidencian un metal adecuado con su funcionalidad y pragmatismo de coste, con calidad de acero hipoeutectoide, utilización de soldadura por capas y singular resistencia a la corrosión. Los ornamentos, de bronce y latón, son suficientemente maleables para facilitar al máximo el detalle artístico y presentan indicios evidentes de reutilización.
\end{abstract}

Palabras clave: Arqueometalúrgia; Catedral de Barcelona; Rejas; Farga catalana; Metalurgia medieval.

\begin{abstract}
In the Barcelona Cathedral remain in use various contemporary bars of the original building. They are made with iron / steel and with decorative elements of copper alloy. Prior to the advances in quality and productivity innovations of the Catalan method of XVII century, it was considered of interest to identify the level of technological development applied by metallographic study. The analysis has consisted to obtain samples for observation in optical microscopy and SEM, micro durometer test and EDAX. Generically, the results show a suitable metal, with "soft iron" (hypoeutectoid steel) quality, a use of welding layers and high corrosion resistance. The ornaments are made from bronze and brass, and they are malleable enough to enable the artistic detail and show obvious signs of reused metal.
\end{abstract}

Keywords: Archaeometallurgy; Barcelona Cathedral; Bars; Catalan method; Medieval metallurgy.

Recibido: 08-09-2014. Aceptado: 14-01-2015.

Cómo citar este artículo / Citation

Auladell Marquès, J. y Simon Arias, J. 2015: "Metalurgia medieval aplicada a la construcción. Las rejas góticas de la Catedral de Barcelona", Arqueología de la Arquitectura, 11: e029. doi: http://dx.doi.org/10.3989/arq.arqt.2015.002

\section{Copyright}

(c) 2015 CSIC. Este es un artículo de acceso abierto distribuido bajo los términos de la licencia Creative Commons Attribution-Non Commercial (by-nc) Spain 3.0. 


\section{INTRODUCCIÓN}

El objetivo del presente artículo se centra en mostrar la siderurgia medieval con fines edificativos en su aplicación práctica. Para ello se identifica el nivel de desarrollo tecnológico precisado para forjar diversas rejas sitas en las capillas de la nave central y el claustro de la Catedral de Barcelona, las cuales se datan en las etapas iniciales de construcción y forman parte del patrimonio gótico del conjunto. Su análisis metalúrgico debe permitir describir calidades del metal, el procedimiento utilizado y la adaptación a las necesidades constructivas; a su vez, faculta la actuación en el ámbito de las tareas de preservación patrimonial, disponiendo de datos físicos referentes a su estado de conservación.

Sin estudio analítico previo de los diversos enrejados y cancelas, el proyecto ha posibilitado diferenciar las reparaciones posteriores y establecer la relación directa entre la metodología de producción y la documentación histórica conservada en el Archivo Capitular de la propia Catedral ${ }^{1}$. A partir de dicha información, se ha procedido a seleccionar aquellas rejas que, supuestamente, corresponden a la obra gótica original ${ }^{2}$.

\section{CONTEXTO HISTÓRICO Y TÉCNOLÓGICO}

Con larga tradición en su estudio histórico-artístico, la construcción de la catedral gótica de Barcelona se inició oficialmente el año 1298 como resultado de la voluntad de substitución del precedente y menor edificio cultual románico que, a su vez, se erigía sobre estructuras paleocristianas. Finalizadas las obras con el claustro y el cimborio provisional durante la segunda mitad del s. $\mathrm{XV}$, la intervención de estilo neogótico (finales s. XIXinicios s. XX) consistió en la culminación de la fachada y el cimborio y la renovación de instalaciones diversas.

El conjunto arquitectónico presenta una basílica con estructura de cruz latina en cuyos extremos del crucero se

\footnotetext{
1 Amenòs, L1. 2004. L'activitat i les produccions dels ferrers en el marc de l'arquitectura religiosa catalana (segles XI-XV), Tesis Doctoral, Universitat de Barcelona.

Farrando, R., Omella, R.: 1996. Les reixes de la Catedral de Barcelona. Voluntarios de la Catedral de Barcelona, edición propia.

2 Auladell, J. y Simon, J. 2012. Anàlisi i estudi arqueometal·lúrgic de les reixes gòtiques de la Catedral de Barcelona. Trabajo de investigación en el marco del convenio interuniversitario Conveni sobre l'estudi tecnològic i estructural dels objectes de ferro protohistòrics del nordest peninsular, entre los grupos de investigación GRAP (UB) y PROCOMAME (UPC) (2008 -2012).
}

sitúan los campanarios, en la base de los cuales se ubican accesos; el cuerpo principal se articula en tres naves y un único ábside, aprovechando los contrafuertes para, interiorizándolos, habilitar capillas auxiliares que circundan el espacio sacro y que, a su vez, perimetran parcialmente el claustro anexo rectangular. La necesidad de distribuir los espacios litúrgicos y proceder a los cerramientos de las capillas y los ventanales al exterior propiciaron la utilización de gran cantidad de estructuras metálicas, principalmente cancelas, barandas, pasamanos, enrejados y portones, que debían añadir a la funcionalidad un componente estético acorde al entorno.

La tecnología siderúrgica medieval consistía en una industria artesanal cuyo proceso se iniciaba en la extracción del mineral, su reducción y la obtención del metal de forma directa ${ }^{3}$, la producción de calidades y formatos estandarizados y su comercialización al maestro forjador, el cual se especializaba en las múltiples aplicaciones del hierro y el acero y adaptaba los procedimientos al encargo a ejecutar. Durante el periodo de producción de las rejas góticas de la Catedral, el proceso se hallaba en una etapa intermedia de desarrollo del llamado método catalán o farga catalana, posterior a la aplicación de la energía hidráulica en la purificación de la esponja de hierro, datada de la primera mitad del s. XII, y anterior a la trompa de aire, innovación del s. XVII (Mascarella 1993: 42-49; Mas 2000: 73-78).

\section{MATERIALES Y MÉTODO}

\subsection{El conjunto muestral}

A las características formales y documentales de los materiales susceptibles de estudio, determinantes de su inclusión en el conjunto muestral, se añaden condicionantes de tipo logístico o patrimonial, tales como el estado de conservación, el uso litúrgico aún vigente, su ubicación en el área cultual o el nivel de protección como elemento singular.

A partir de las premisas anteriores se ha procedido a la extracción de diecinueve muestras correspondientes a siete rejas bibliográficamente enmarcadas en el período histórico de interés. De las muestras obtenidas, trece se

\footnotetext{
El método directo implica la reducción del mineral a metal en estado sólido, obteniendo una masa pastosa o esponja; es el propio de la siderurgia tradicional, en el que la infraestructura (horno) y el combustible (carbón vegetal) no permiten alcanzar la temperatura de fundición del metal. Se contrapone a su obtención en estado líquido, el método indirecto, proceso generalizado en Occidente a partir de la Revolución Industrial.
} 
obtienen de la estructura de barras y pasamanos y de los elementos de fijación, de hierro o acero; las seis muestras restantes proceden de los elementos ornamentales, con unas características físicas propias del cobre y sus aleaciones.

En el presente resumen se incluyen únicamente cinco muestras del total del conjunto, correspondientes a las rejas de cerramiento de las capillas referenciadas en la figura 1 con los números 1,2 y 7 :

- Enrejado 1: instalado el año 1450; se vinculan las muestras 0101 y 0102.

- Enrejado 2: instalado el año 1568; se vinculan las muestras 0201 y 0203.

- Enrejado 7: instalado el año 1367; se vincula la muestra 0701.

\subsection{El método experimental}

La metodología de trabajo experimental se ha orientado a la identificación de las características tecnológicas de las rejas originales. Con esta finalidad se llevan a cabo los siguientes estudios analíticos:

- Metalografía de la estructura cristalina mediante observación microscópica óptica y electrónica de barrido (SEM).

- Microanálisis químico cualitativo y semicuantitativo por dispersión de energía de rayos X (EDAX), de aplicación en la estructura cristalina y en las fases mineralógicas de las inclusiones no metálicas atrapadas en el metal.

- Determinación de la dureza de las distintas estructuras metálicas mediante la técnica microdurométrica.

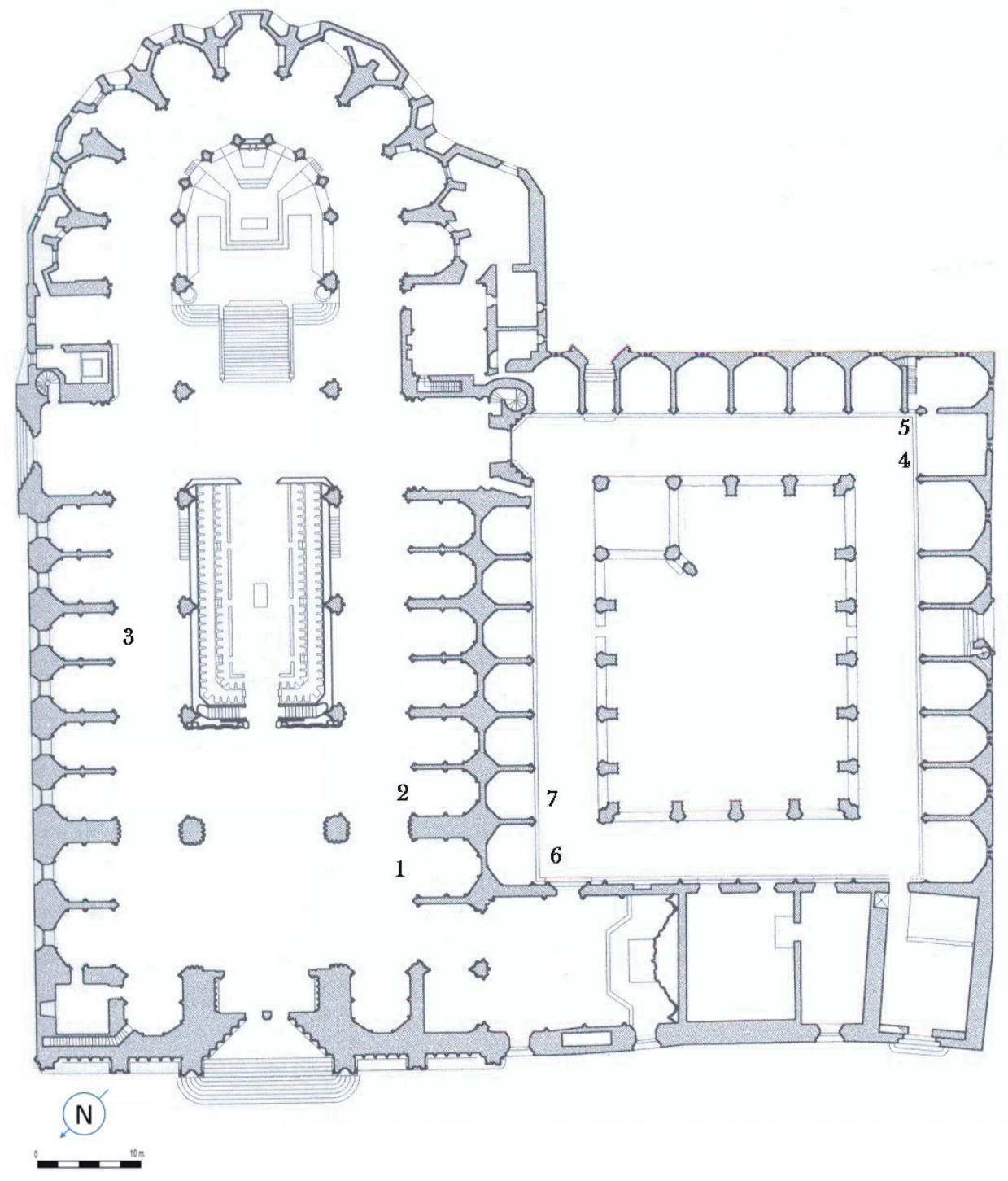

Figura 1. Planimetría de la Catedral de Barcelona con la situación de las capillas originarias del conjunto muestral del estudio y las citadas en el presente artículo (capillas 1, 2 y 7). 
El procedimiento seguido se ajusta a la metodología clásica de preparación de muestras metalográficas y posterior investigación ${ }^{4}$.

\section{RESULTADOS}

\subsection{Estudio arqueometalúrgico del enrejado 1}

La reja estudiada corresponde al cierre de la capilla dedicada en inicio a Santa Clara y Santa Catalina que, a partir de 1840, modificó el culto a la veneración de San Clemente (figura 2).

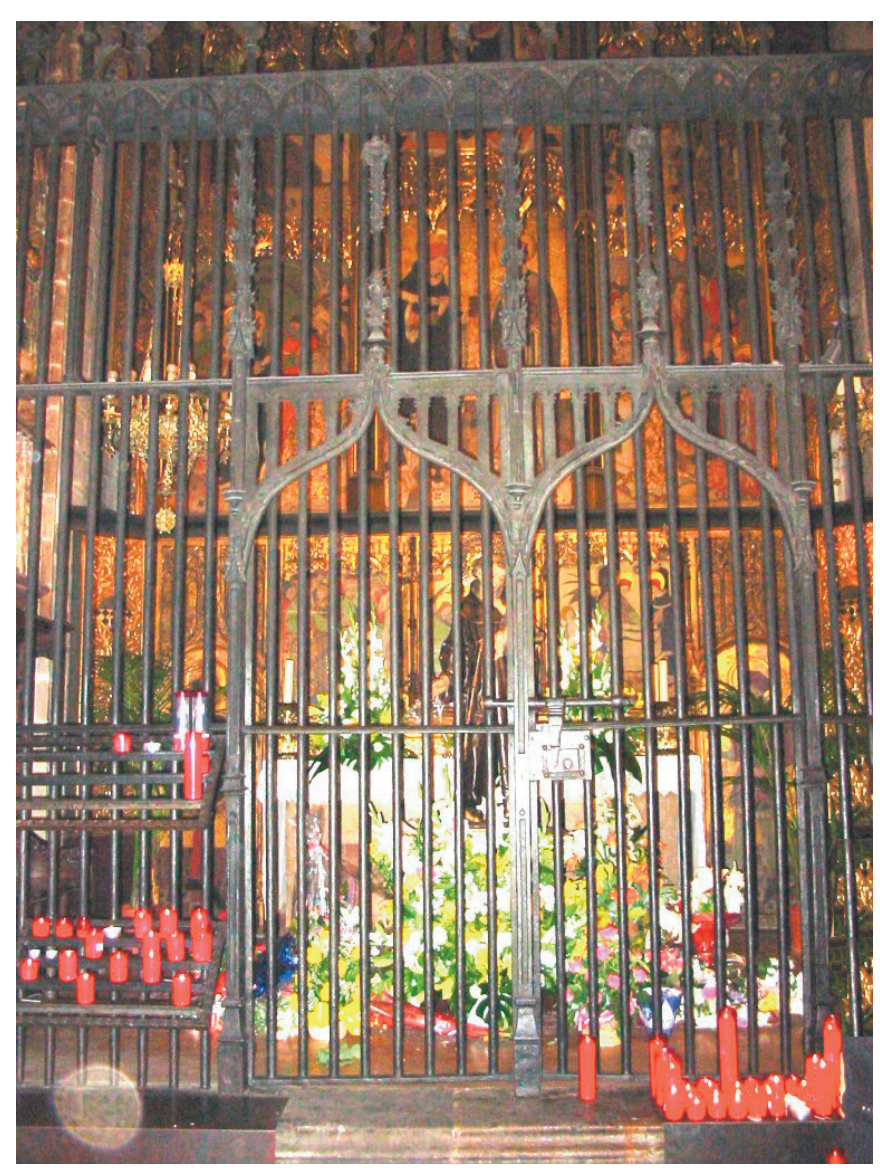

Figura 2. Imagen genérica del enrejado 1 (capilla de San Antonio de Padua y de los Santos Cosme y Damián).

\footnotetext{
4 Se separan las muestras por corte mecánico refrigerado y se obtienen superficies de estudio para encastar y posibilitar su desbaste, micropulido y ataque químico como estadio previo a la observación microscópica y a la posterior analítica. El equipo básico utilizado corresponde a una cortadora portátil rotatoria Dremel 300 para la extracción in situ, una lupa estereoscópica Nikon, una encastadora SpeedPress Buehler, dos microscópicos ópticos metalográficos, un PhotoMicroscope II C.Zeiss y un Olympus GX51 (software Omnimet), un indentador VickersHardness Matsuzawa Seiks DMH-1 y un microscopio electrónico de barrido JEOL JSM-6400 con espectrómetro de energía de dispersión de rayos X Link Analytical LZ-5.
}

La elaboración de la reja se data en 1450, obra del artesano barcelonés Joan Vilalta, por encargo de Sança Ximenis de Foix y de Cabrera, esposa de Arquimbau de Foix, con un valor de 335 florines de oro. Existe constancia documental de dicho encargo y del pago por parte de la misma patrocinadora de 55 florines más al pintor Joan Cabrera para dorar parte de la estructura metálica (Farrando y Omella 1996: 30; Amenós 2004: 137-138).

De estructura recargada, se elaboró a partir de un cuerpo central con acceso de doble batiente y laterales con continuidad de barrotes y pasamanos. En un estado de conservación aparentemente correcto, la presente reja se caracteriza por la ornamentación propia del gótico florido, con arcos conopiales sobre el umbral, gabletes, soportes de figuras escultóricas flanqueantes, hoy ausentes, y ornamentación floral de coronamiento formando crestería, con grandes frutos, posiblemente granadas, y todo tipo de hojas lobuladas también presentes en la culminación superior de los barrotes y en los bastidores: cardinas, hojas de vid, de roble, de trébol, espigas y palmas. Con presencia de añadidos más modernos, presenta marco moldurado clavado en el pavimento, de doble puerta con bastidor central y triple pasamano afianzado en los laterales. El pasamano central destaca por una acanaladura lateral de borde inferior redondeado, detalle diferenciador y evidente de una factura esmerada.

\subsubsection{Muestra 0101}

Obtenida del pasamano o primer travesaño horizontal y forjada en hierro o acero.

\section{Descripción del metal y estudio analítico}

La muestra presenta una microestructura con heterogénea gradación de carbono (C), siendo la zona más interna del pasamano casi ferrítica $(104,1 \mathrm{HV})^{5}$, con inclusiones no metálicas agrupadas y de pequeño o mediano tamaño; $\sin$ indicios de deformación ni de carburación en sus límites, el grano ferrítico presenta tamaño medio uniforme.

Se observa una transición repentina a la estructura hipoeutectoide con disposición Widmanstätten (134,3 $\mathrm{HV}$ ) que evoluciona hasta el eutectoide (182,7 HV), con granulometría acicular e inicial presencia de cementita terciaria intergranular. Decreciendo el contenido de C en dirección a la superficie de la muestra, se aprecia una microestructura casi ferrítica muy cercana a la cara perimetral; en la zona ya superficial, con enriquecimiento

\footnotetext{
5 Las microdurezas practicadas en las muestras de estudio se expresan en unidades Vickers (Hardness Vickers).
} 
de C, aparecen granos de perlita (160,6 HV) y ferrita acicular que contrastan con la microestructura anterior (figuras 3a-3d) .

A mayor aumento, se detalla la carburación superficial y una tipología de las inclusiones no metálicas que difiere visualmente de las identificadas en el área interior de la muestra. En una ubicación intermedia de la muestra, y formando una banda paralela a la cara superior, la zona de mayor carburación presenta una microestructura hipereutectoide, con cementita intergranular en los límites de grano perlítico. A fin de detectar cualquier elemento minoritario que afecte las características y propiedades de la matriz metálica, el correspondiente análisis semicuantitativo atestigua un metal de hierro químicamente casi puro.

En referencia a las inclusiones no metálicas de supuesta naturaleza cristalina se han realizado "mappings" de identificación individualizada de componentes elementales ${ }^{6}$. Se procede a diferenciar dos variantes formales de inclusiones, unas de formato irregular (figura 3e) y otras circulares o anulares (figura 3f); las inclusiones de forma más irregular corresponden a nódulos de óxidos de hierro, probablemente wustita; las inclusiones circulares son formadas por silicato de calcio-magnesio, con un nódulo de wustita $(\mathrm{FeO})$ en el centro de aquellas anulares, donde el manganeso $\left(\mathrm{Mn}^{2+}\right)$ ha substituido parcialmente al hierro $\left(\mathrm{Fe}^{2+}\right)$.

\section{Interpretación}

La interpretación de los resultados obtenidos queda limitada por el hecho de no disponer de una sección entera del pasamanos y reducirse la muestra a un fragmento de uno de los ángulos de su cara superior.

Respecto a la presencia de inclusiones diversas, algunas de primera obtención ${ }^{7}$ y otras derivadas de los trabajos sobre el metal, evidenciarían las obvias dificultades en la depuración durante el proceso de postreducción y forja, propias de la tecnología del momento. La heterogeneidad de microestructuras identificadas y la discontinua presencia de inclusiones no metálicas indican el uso de diferentes porciones de metal, láminas u otros fragmentos. El estudio de la muestra presume un mínimo de dos, diferenciadas por el diverso porcentaje de inclusiones y por el súbito cambio microestructural, que pasa al eutectoide en el área central de la muestra.

\footnotetext{
${ }_{6}$ En los "mapping" la densidad de puntos blancos indica la gradación en la presencia del correspondiente elemento.

Ya detectables en el producto original de la reducción.
}

El pasamanos fue trabajado mecánicamente en caliente, a temperatura superior o igual a la de recristalización, evitando la deformación del grano para, finalmente, ser cementado depositando la cara plana más ancha sobre las brasas, circunstancia que le proporcionó un enriquecimiento de carbono muy superficial, con poca penetración (inferior a $0,1 \mathrm{~mm}$ ), que no se repitió en el lado estrecho observado.

En referencia a las inclusiones no metálicas, el análisis muestra los elementos habituales que forman las fases típicas de las escorias de obtención directa, con nódulos formados por wustita $(\mathrm{FeO})$, una fase cristalina fayalítica $\left(\mathrm{Fe}_{2} \mathrm{SiO}_{4}\right)$ y un fondo de silicato actuando como remanente de los elementos menos abundantes y parte del sílice presente. La wustita identificaría escorias de primera reducción, originarias del mineral, y mostraría un proceso de depuración incompleto, incapaz de extraer las impurezas del metal. Destaca la presencia de fósforo (P) y azufre (S): en el caso del $\mathrm{P}$, su existencia en las inclusiones está vinculada al mineral original de hierro; respecto al hallazgo de $\mathrm{S}$, las hipótesis relativas a su presencia son diversas: una contaminación durante la forja del útil por impregnación de restos de metales previamente trabajados, por la existencia de sulfuros originarios en el combustible o, probablemente, por formar parte del mineral original, como el P. La presencia de potasio $(\mathrm{K})$ y calcio $(\mathrm{Ca})$ se encontraría asociada, respectivamente, al combustible utilizado, carbón vegetal, y a las reacciones químicas que, durante la reducción, se producen con los silicatos de la arcilla que forma las paredes internas del horno (Simon 1992: 107-124).

El objeto se conformó a partir de porciones de acero con diferente grado de carburación y soldadas a la calda, quedando poco acerado en la cara superior. Descarburado durante el trabajo en caliente, fue enfriado a suficiente velocidad (sin temple) para formar una estructura acicular típica (Widmanstätten), y se procedió a una última cementación para aumentar la dureza perdida durante la conformación.

\subsubsection{Muestra 0102}

Obtenida de una de las molduras decorativas del marco del acceso. A diferencia de la estructura férrica a la que se sujeta, está elaborada con cobre o una de sus aleaciones.

\section{Descripción del metal y estudio analítico}

La microestructura observada se caracteriza por dos fases, una de tonalidad clara (64 HV) y otra más oscura 


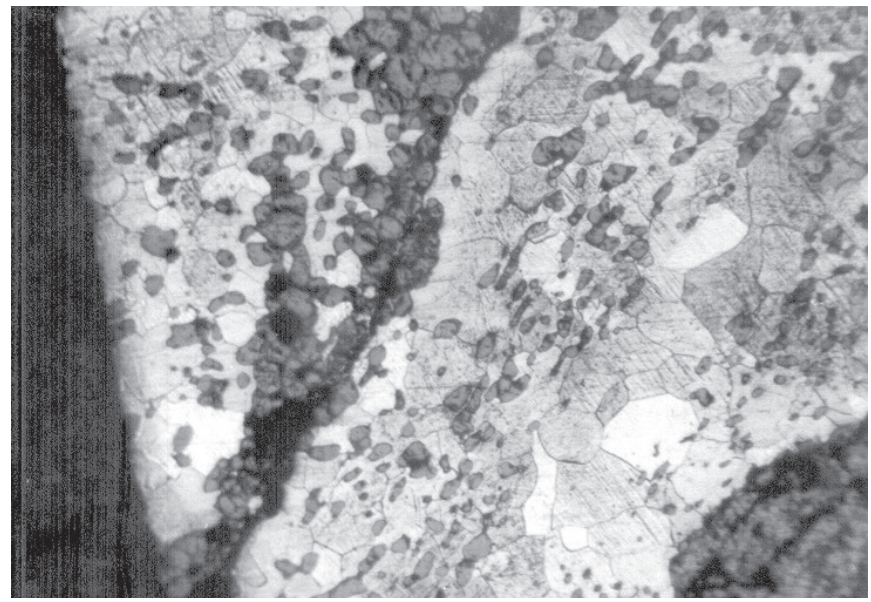

Figura 3a. Imagen de microestructura ferrítica hipoeutectoide con numerosas inclusiones no metálicas ( 220 augm.).

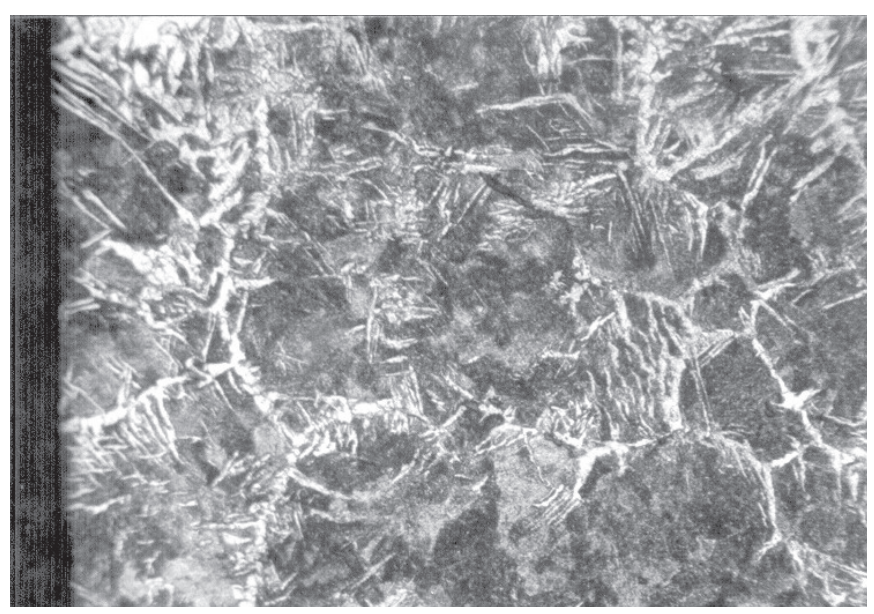

Figura 3c. Imagen de área con microestructura casi eutectoide; posible presencia de cementita intergranular (x 220 augm.).
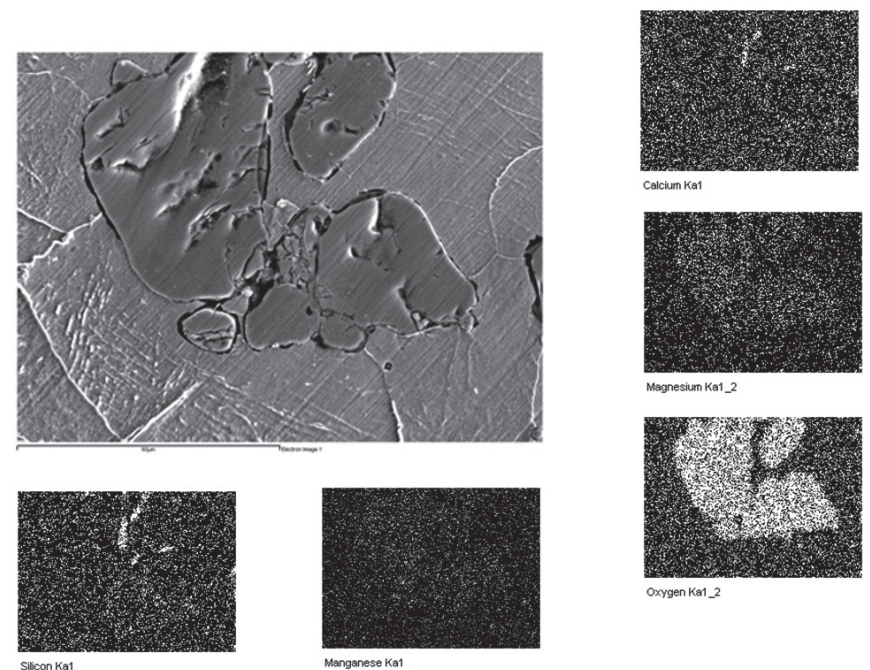

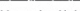

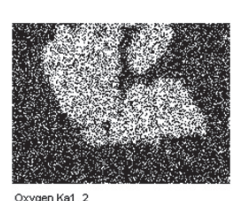

Figura 3e. Imagen de inclusión no metálica de forma irregular sobre la matriz metálica. Se incluye "mapping" de presencia de elementos $\left(\mathrm{Ca} / \mathrm{Mg} / \mathrm{O}_{2} / \mathrm{Si} / \mathrm{Mn}\right)$.

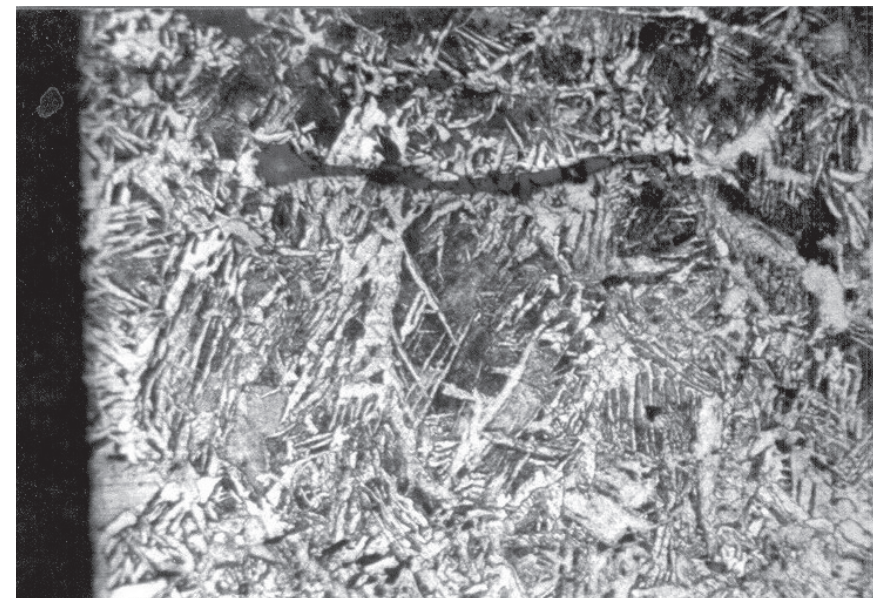

Figura 3b. Imagen de transición del hipoeutectoide en disposición Widmänstatten a área de mayor carburación (x 220 augm.).

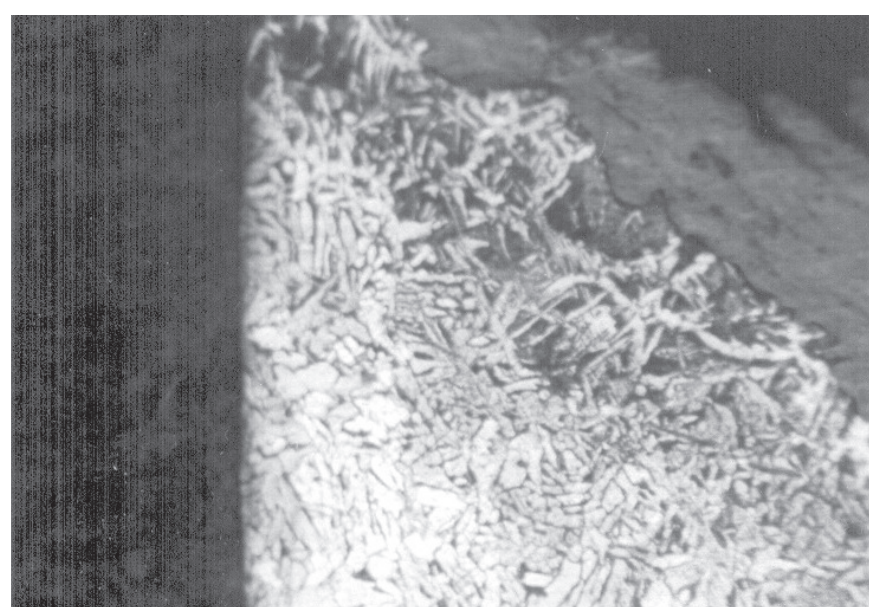

Figura 3d. Imagen de sección cercana a la cara superficial de la muestra con microestructura hipoeutectoide, más carburada en la zona perimetral (x 220 augm.).
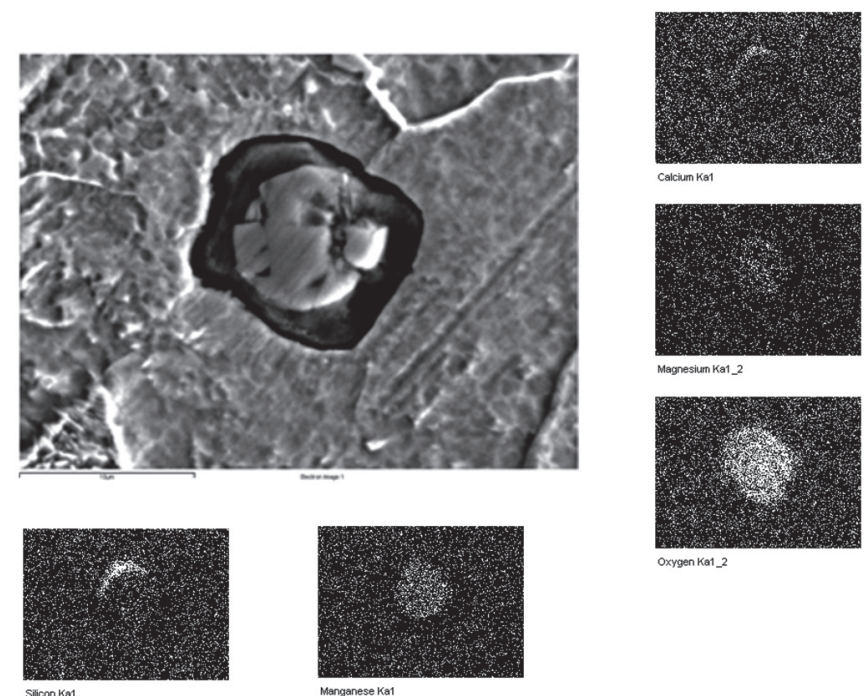

Figura 3f. Imagen de inclusión no metálica de forma circular-anular sobre la matriz metálica. Se incluye "mapping" de presencia de elementos $\left(\mathrm{Ca} / \mathrm{Mg} / \mathrm{O}_{2} / \mathrm{Si} / \mathrm{Mn}\right)$. 
(64,9 HV), de carácter totalmente dendrítico, entre las que se desarrollan numerosas y diversas inclusiones generalizadas en la superficie de estudio (figura 4).

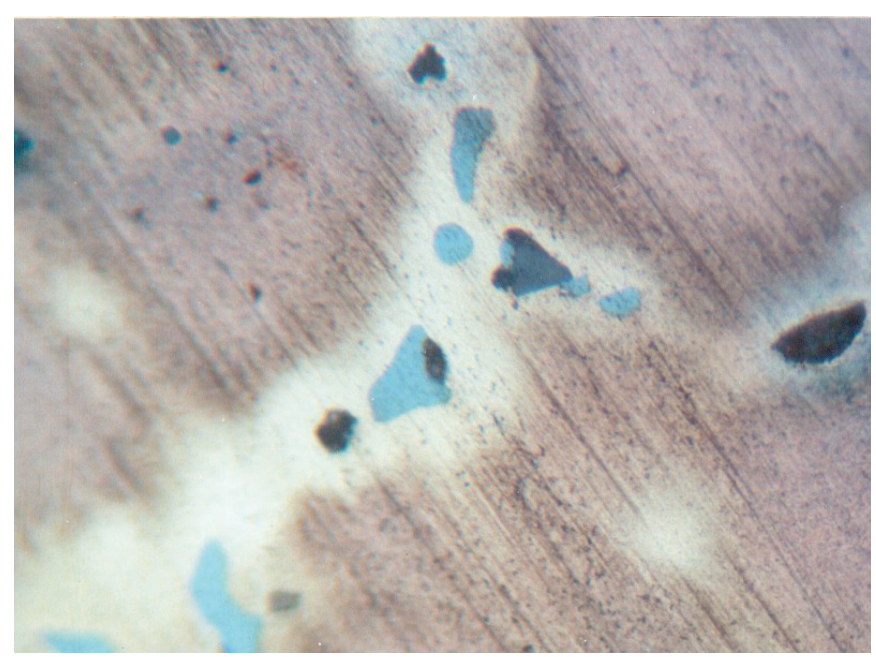

Figura 4. Fotomicrografía de la muestra 0102 con imagen de las dos fases visibles e inclusiones de diversa naturaleza (x 960 augm.).

Se ha procedido a analizar la matriz metálica comprobando la presencia mayoritaria de cobre $(\mathrm{Cu}) \mathrm{y}$, en menor proporción, de plomo $(\mathrm{Pb})$, zinc $(\mathrm{Zn})$ y estaño $(\mathrm{Sn})$. Asimismo, se han identificado ambas fases y se ha procedido a su análisis semicuantitativo junto al de las inclusiones: en la matriz, la fase oscura se encuentra formada por $\mathrm{Cu}$ y la más clara con $\mathrm{Cu}$ como elemento mayoritario y $\mathrm{Sn}$ y $\mathrm{Pb}$ como minoritarios; en referencia a las inclusiones, se distinguen físicamente dos tipologías por morfología y cromatismo; las inclusiones negras están en su mayor parte formadas por $\mathrm{Pb}$ y las de tonalidad azul por azufre (S) y Zn (tabla 1).

\section{Interpretación}

El grano dendrítico de la matriz metálica es el propio de un enfriamiento rápido desde el estado líquido. Los análisis confirman que se trata de una pieza de broncelatón compuesta por los elementos $\mathrm{Cu}-\mathrm{Sn}-\mathrm{Zn}-\mathrm{Pb}$. Durante el proceso de solidificación se formaron dos fases: una prácticamente de cobre puro, y la otra de un bronce ternario compuesto por $\mathrm{Cu}-\mathrm{Sn}-\mathrm{Pb}$; la mayor parte del plomo, metal con punto de fusión inferior, se segregó durante la solidificación creando inclusiones en los límites de grano de la aleación. En el mismo orden, se ha evidenciado en las inclusiones de tonalidad azulada los elementos S y Zn, que han formado sulfuro de zinc; posteriores espectros cualitativos revelan la presencia de hierro $(\mathrm{Fe})$ como elemento traza, en forma de impureza y considerada posible huella identificadora del mineral originario.

Desde la antigüedad, el procedimiento de elaboración de objetos de bronce empleaba metales de primera utilización y, como alternativa, metales reutilizados a partir de objetos en desuso o amortizados, técnica de interés ante la posible escasez en el suministro de materia prima. La aleación cuaternaria faculta la posibilidad de la utilización de más de un objeto refundido en la elaboración de la pieza; a su vez, el original se elaboró a partir de un molde, donde el metal llegó en estado fluido. Durante la observación microscópica no se han detectado burbujas dejadas por el gas, lo que indicaría una técnica de moldeo eficiente en la que el fundidor demuestra el conocimiento empírico de situar adecuadamente la alimentación del metal respecto a la geometría de la pieza. El procedimiento óptimo corresponde a poner el molde en una posición que permita que la solidificación del objeto se inicie en la

\begin{tabular}{|c|c|c|c|c|c|c|c|c|}
\hline Spectrum & $\mathbf{C}$ & $\mathbf{O}$ & $\mathbf{S}$ & $\mathrm{Cu}$ & Zn & Sn & $\mathbf{P b}$ & Total \\
\hline Spectrum 2 & 3.99 & & & 96.01 & & & & 100.00 \\
\hline Spectrum 3 & & 0.70 & & 95.85 & & 1.88 & 1.57 & 100.00 \\
\hline Spectrum 4 & 5.02 & 2.77 & & 18.91 & & & 73.30 & 100.00 \\
\hline Spectrum 5 & 6.30 & & & 93.70 & & & & 100.00 \\
\hline Spectrum 6 & 5.67 & 0.25 & & 92.35 & & 1.73 & & 100.00 \\
\hline Spectrum 7 & 3.75 & & 8.38 & 51.32 & 36.54 & & & 100.00 \\
\hline Spectrum 8 & 3.21 & & 18.49 & 7.10 & 71.19 & & & 100.00 \\
\hline Spectrum 9 & & 0.72 & & 94.29 & & 2.35 & 2.63 & 100.00 \\
\hline Max. & 6.30 & 2.77 & 18.49 & 96.01 & 71.19 & 2.35 & 73.30 & \\
\hline Min. & 3.21 & 0.25 & 8.38 & 7.10 & 36.54 & 1.73 & 1.57 & \\
\hline
\end{tabular}

Tabla 1. Análisis semicuantitativo del metal y las inclusiones en la muestra 0102 (\% en peso). Identificación: spectrum 2: área marrón oscura del metal; spectrum 3: área marrón clara del metal; spectrum 4: inclusión negra; spectrum 5: área marrón oscura del metal; spectrum 6: área marrón clara del metal; spectrum 7: inclusión azul; spectrum 8: inclusión azul; spectrum 9: área marrón clara del metal. 
parte baja de dicho molde y siga progresivamente hacia arriba, eludiendo el riesgo de que se formen perniciosas burbujas de gas en el metal sólido.

Actualmente se añade plomo al bronce para mejorar su maquinabilidad y resistencia al desgaste. Su uso en la muestra indicaría dos posibilidades no excluyentes: que se utilizara intencionadamente por su moldeabilidad y la no necesidad de otras propiedades mecánicas en la pieza original, lo que afirmaría un conocimiento de dicho beneficio ya documentado en la metalurgia preindustrial; por otra parte, y de forma pragmática, el uso de plomo podría vincularse al simple abaratamiento en el coste del producto.

\subsection{Estudio arqueometalúrgico del enrejado 2}

La reja objeto de estudio corresponde al cierre de la capilla bajo advocación de Sant Josep Oriol (figura 5), la cual, con anterioridad al culto del santo barcelonés, estaba consagrada a San Agustín y al también local obispo Sant Oleguer, cuyos restos permanecieron depositados en dicho espacio entre 1380 y 1936 (Martí 2003: $10-11)^{8}$. Si bien es posible la existencia de una reja contemporánea a la instalación de las reliquias correspondientes, tal vez de madera o también metálica, la documentación histórica precisa que la estructura actual fue forjada por el maestro Joan Sort en 1568, al precio de 200 libras barcelonesas (Farrando y Omella 1996: 29), y posteriormente restaurada durante la intervención del s. XIX (Amenós 2004: 142)9.

En estado de conservación aparentemente correcto, la reja de la capilla de Sant Josep Oriol se caracteriza por, siendo de cronología posterior a las rejas de la etapa de construcción del conjunto, continuar el modelo de ornamentación de gótico florido. Sin embargo, son posibles añadidos posteriores los que en buena parte motivan el estilo tardío y recargado, con presencia de decoración sobrepuesta en el cuarto superior de los batientes rectangulares de arcos conopiales rematados por palmas de tres ramas, gabletes laterales, soportes de figuras escultóricas, hoy ausentes, y ornamentación floral abundante de coronamiento; también con añadidos, muestra marco cuadrado y moldurado clavado en

\footnotetext{
8 La tradición indica que los restos de Sant Oleguer (1060-1137), obispo de Barcelona y arzobispo de Tarragona, se mantuvieron incorruptos hasta que se trasladaron con motivo del inicio de la Guerra Civil (1936-39).

9 Ll. Amenós considera la reja de Sant Oleguer neogótica dado el documento de intervención del artesano F. Deop entre 1878 y 1880. A pesar de ello, los indicios preliminares y los resultados posteriores relativizan la actuación moderna en la reja, tratándose posiblemente de una reparación de la vieja estructura del s. XVI.
}

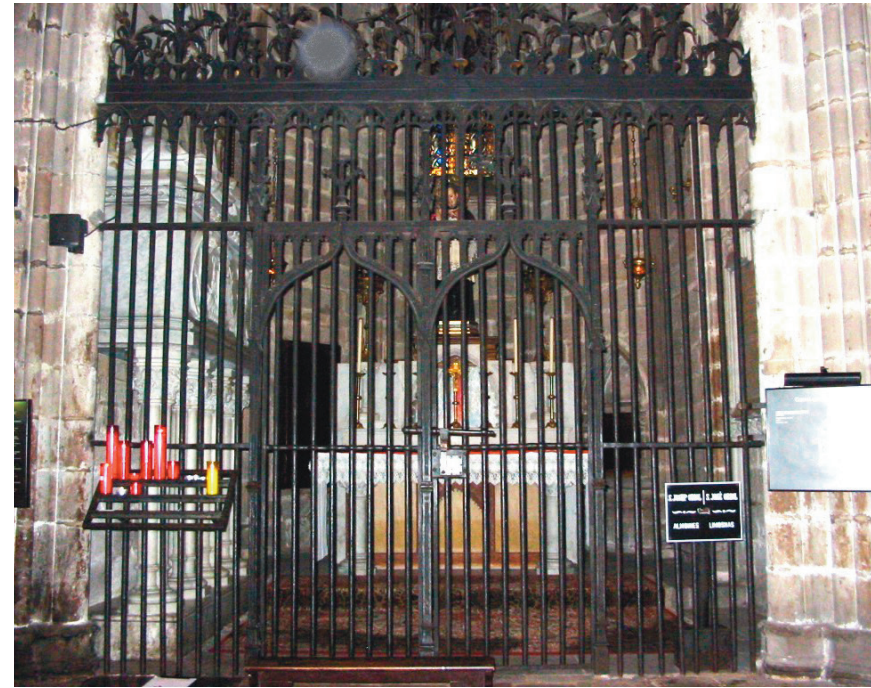

Figura 5. Imagen genérica del enrejado 2 (capilla de Sant Josep Oriol).

el pavimento, doble batiente con bastidor central, triple pasamano de sección cuadrangular afianzado en los laterales y barrotes coronados por pomos alternados de hojas y flores abiertas, con la cruz de la Catedral como motivo central.

\subsubsection{Muestra 0201}

Obtenida del pasamano o primer travesaño horizontal y forjada en hierro o acero.

\section{Descripción del metal y estudio analítico}

La muestra se caracteriza microestructuralmente por una matriz metálica casi ferrítica $(84,1 \mathrm{HV})$ con alguna cadena de cementita terciaria intergranular y granulometría sin deformación. De forma minoritaria y en la zona superficial se localiza la existencia de pequeños granos perlíticos en los límites granos ferríticos $(90,4 \mathrm{HV})$. El análisis cualitativo puntual de los elementos constituyentes en diferentes zonas de la matriz metálica muestra el hierro $(\mathrm{Fe})$ como único elemento junto, en mínima proporción, del carbono (C).

Se identifican numerosas inclusiones no metálicas distribuidas por la matriz, si bien en diferente cantidad y características morfológicas. Por una parte, inclusiones dispuestas en los límites de los granos ferríticos; su análisis cualitativo indica $\mathrm{Fe}$, manganeso $(\mathrm{Mn})$ y oxígeno $\left(\mathrm{O}_{2}\right)$, correspondiente, por tanto, a una inclusión de wustita $(\mathrm{FeO})$ en la que se ha producido la sustitución parcial de $\mathrm{Fe}^{2+}$ por $\mathrm{Mn}^{2+}$. Por otra, en áreas cercanas a las anteriores, son visibles inclusiones caracterizadas por diferentes fases y con nódulos internos (figura 6); los análisis semicuantitativo correspondientes no han 


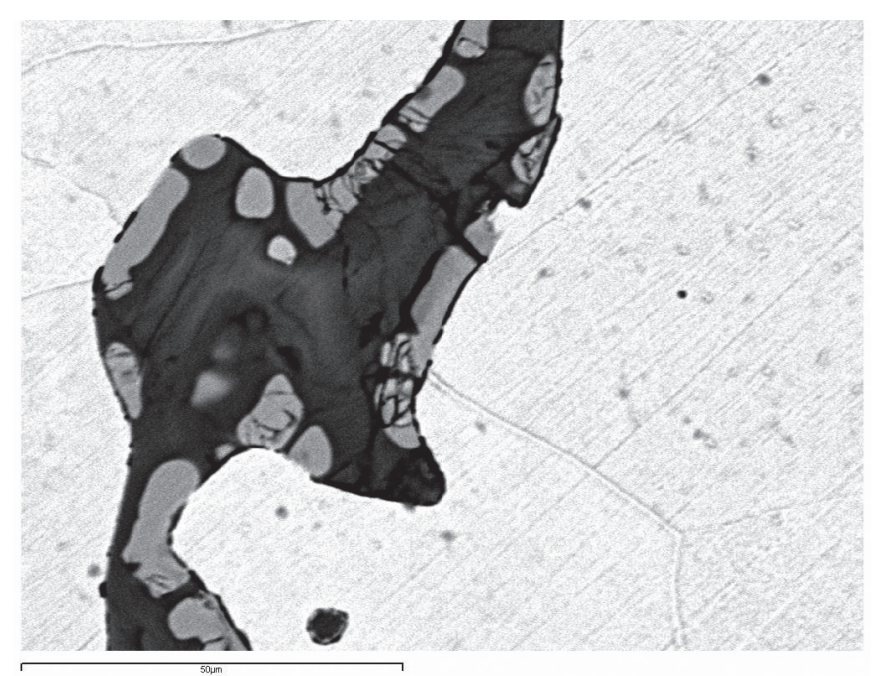

Figura 6. Fotomicrografía de la muestra 0201 con detalle de una inclusión no metálica sobre la granulometría ferrítica, con nódulos y al menos dos tonalidades de fondo.

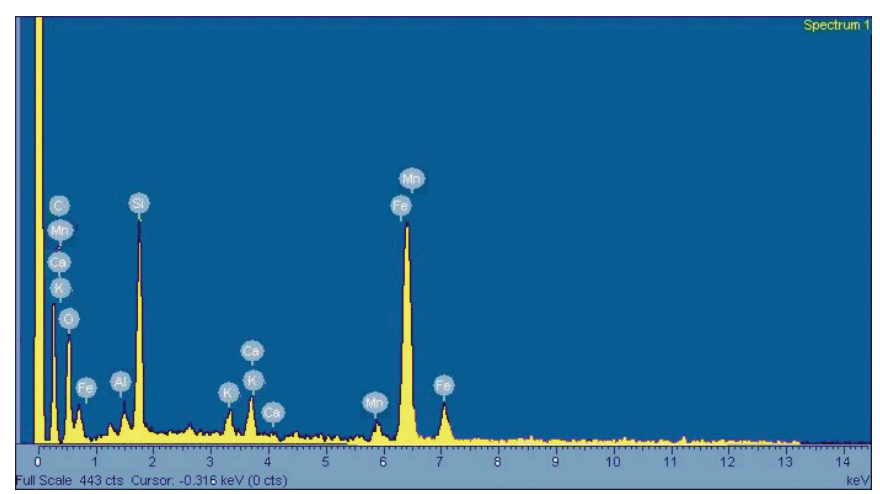

Figura 7. Análisis cualitativo de los elementos constituyentes de una inclusión no metálica en la muestra 0201.

ofrecido resultados concluyentes en referencia a los nódulos, debido a su escaso grosor, si bien una hipótesis sería considerarlos óxidos de hierro; el espectro del fondo de la inclusión indicaría la presencia de fayalita, con el silicio ( $\mathrm{Si}$ ) sobrante formando un remanente de silicato vítreo junto a los elementos presentes en menor proporción (figura 7).

\section{Interpretación}

La muestra estudiada presenta una estructura casi ferrítica, con un ligero porcentaje de carbono en el límite de la cara vista. Partiendo de la hipótesis que se trata de un producto de la farga catalana es factible o que el metal original ya presentara distribución aleatoria de $\mathrm{C}$ desde la reducción, o que a lo largo del procedimiento de conformación se produjera una cementación superficial al apoyar la pieza sobre las brasas, con penetración de $\mathrm{C}$ a profundidad muy limitada. En ambos supuestos no parece que existiera voluntariedad respecto a la ubicación de las zonas aceradas, ya que dichas áreas no precisaban cualidades de dureza singulares.

La microestructura muestra una granulometría regular, sin deformación y tamaño bastante uniforme, que indicaría trabajo mecánico en caliente, a temperatura suficiente para permitir la recristalización simultanea a la deformación plástica. La estructura metálica observada es propia del producto que ha sido sometido a un recocido contra la acritud; este procedimiento se efectúa entre $600^{\circ}$ $\mathrm{C}$ y $750^{\circ} \mathrm{C}$ y aumenta la ductilidad del acero de poco contenido en $\mathrm{C}$ (menos del 0,4\%) estirado en frío; calentando el objeto a esta temperatura, empíricamente detectada a partir del color rojo cereza, se elimina la cristalización alargada de la ferrita, creándose nuevos cristales poliédricos más dúctiles que los primitivos que permiten estirar o laminar nuevamente el material sin mayor dificultad.

Las abundantes y diversas inclusiones son indicativas de una ineficiencia del purificado de la esponja original, habitual en las producciones siderúrgicas antiguas y medievales; tampoco el posterior trabajo mecánico logró la expulsión efectiva de las inclusiones, mermando las propiedades mecánicas de la pieza. Las inclusiones complejas que aparecen en las analíticas presentan los elementos habituales de las escorias del método de obtención directa, con nódulos formados por wustita, un fondo gris claro de naturaleza cristalina de fayalita y un fondo oscuro vítreo de silicato que actúa como remanente. En el mismo sentido, la presencia de potasio $(\mathrm{K})$ y calcio $(\mathrm{Ca})$ se encontraría vinculada, respectivamente, el combustible utilizado, carbón vegetal, y restos originarios de la reacción con los componentes internos de las paredes de la infraestructura.

El pasamanos se conformó aprovechando los diversos formatos estandarizados producidos por la farga catalana (Molera y Barrueco 1983: 24), con una calidad de acuerdo con las necesidades mecánicas. No era preciso un metal especialmente duro para montar la reja sino ductilidad para, entre otros procedimientos, perforar el paso de los barrotes, por lo que se utilizó hierro o acero muy dulce.

\subsubsection{Muestra 0203}

Obtenida de un elemento floral decorativo, una hoja de hiedra, que coronaba un gablete del bastidor de acceso. Muestra elaborada con cobre o una de sus aleaciones.

\section{Descripción del metal y estudio analitico}

Se observa una microestructura dendrítica muy fina, formada por dos fases, una oscura $(78,2 \mathrm{HV})$ y otra de 


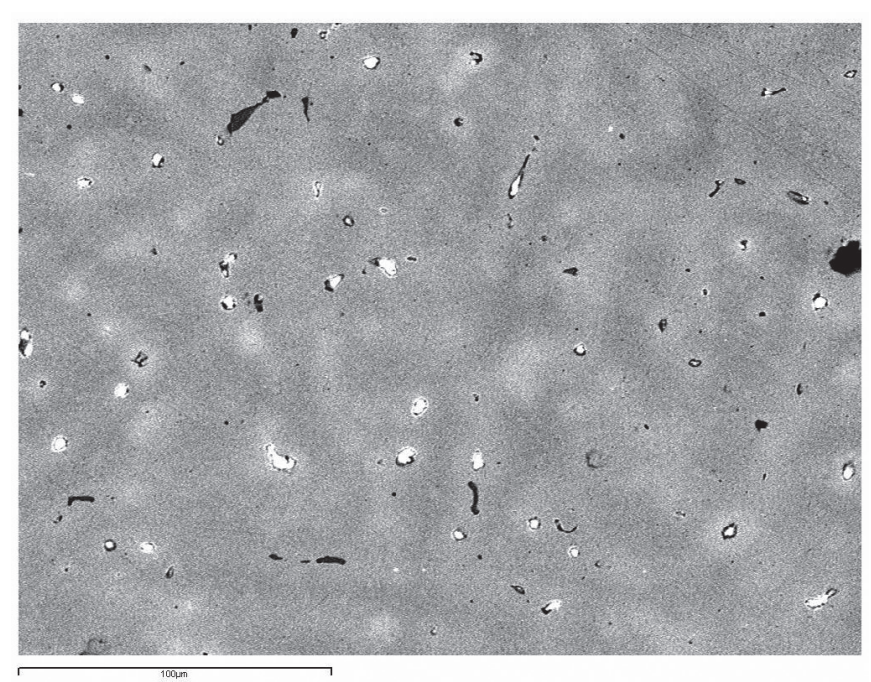

Figura 8. Fotomicrografía de la muestra 0203 con imagen de las dos fases visibles e inclusiones no metálicas.

color claro, casi blanco (63,7 HV), siendo visibles inclusiones diversas (figura 8).

Se han practicado análisis semicuantitativos a la matriz metálica y a las inclusiones de tipología diferente. En la matriz se advierte la presencia mayoritaria de cobre $(\mathrm{Cu})$ con zinc $(\mathrm{Zn}) \mathrm{y}$, en menor proporción, estaño $(\mathrm{Sn})$, plomo $(\mathrm{Pb})$ y arsénico (As) (tabla 2); de los anteriores, el $\mathrm{Cu}$ y el As minoritario parecen corresponder al componente de la fase oscura y la aleación del Cu-Zn$\mathrm{Sn}$ a la fase más clara. El $\mathrm{Pb}$ aparece como componente segregado formando inclusiones metálicas, visibles como blancas en la fotomicrografía del SEM, que pueden resultar arrancadas en ocasiones por el pulido de preparación de la muestra; a ellas se unen los poros, en color negro, habituales en las muestras analizadas.

\begin{tabular}{|c|c|c|c|c|c|}
\hline Element & App & Intensity & Weight\% & Weight\% & Atomic\% \\
\hline & Conc. & Corrn. & & Sigma & \\
\hline $\mathrm{Cu} \mathrm{K}$ & 602.27 & 1.0047 & 89.88 & 3.21 & 93.00 \\
\hline $\mathrm{Zn} \mathrm{K}$ & 22.56 & 1.0093 & 3.35 & 2.28 & 3.37 \\
\hline $\mathrm{As} \mathrm{L}$ & 4.05 & 0.4047 & 1.50 & 1.48 & 1.32 \\
\hline $\mathrm{Sn} \mathrm{L}$ & 14.99 & 0.8309 & 2.71 & 1.41 & 1.50 \\
\hline $\mathrm{Pb} \mathrm{M}$ & 11.57 & 0.6768 & 2.56 & 1.57 & 0.81 \\
\hline Totals & & & $\mathbf{1 0 0 . 0 0}$ & & \\
\hline
\end{tabular}

Tabla 2. Análisis semicuantitativo de la matriz metálica de la muestra 0203 ( $\%$ en peso).

\section{Interpretación}

La muestra presenta una estructura dendrítica fina producto de un enfriamiento muy rápido, sin duda motivado al verter el metal en estado líquido en un molde frío (a temperatura ambiente) y por las propias características físicas del objeto, de pequeñas dimensiones.

La funcionalidad ornamental de la pieza explica la composición de la aleación empleada, un bronce arsenicado o latón inferior $(<5 \% \mathrm{Zn})$, si bien la superior cantidad de $\mathrm{Zn}$ respecto del $\mathrm{Sn}$ hace más cercana su asignación al grupo de los latones. Esta tipología de aleación, de color oro viejo, resulta distintiva por su ductilidad e indicada en trabajos de orfebrería, joyería o decoración; a dichas propiedades se añaden las cualitativas generadas por el Sn y la maquinabilidad y facilidades para la fundición y moldeo proporcionadas por el $\mathrm{Pb}$.

Como hipótesis de trabajo se interpreta que la experiencia empírica del artesano permitió vincular la utilidad de la pieza con el material metálico a emplear, combinando buenas propiedades para la fundición y moldeado con el color más interesante para el ornamento. El metal base fue posiblemente obtenido del reciclaje de diferentes objetos: uno de bronce ternario $(\mathrm{Cu}-\mathrm{Sn}-\mathrm{Pb})$ de donde provendrían el arsénico, propio del mineral de obtención de $\mathrm{Cu}$; por otra parte, un latón $\mathrm{Cu}-\mathrm{Zn}$. La presencia de arsénico faculta la reutilización de un utensilio antiguo, conformado a partir de $\mathrm{Cu}$ arsenical o de bronce formado por esta aleación natural; el porcentaje de As presente testimoniaría una gran cantidad del elemento en la pieza original.

\subsection{Estudio arqueometalúrgico del enrejado 7}

Capilla de inicial advocación a San Mateo y San Matías (figura 9), en el 1367 el mercader de Barcelona Guillem Almugaver ofreció 100 libras para forjar la reja correspondiente, motivo por el que se añadió su escudo heráldico flanqueando el doble acceso (Farrando y Omella 1996: 52). Se trata de uno de los elementos de hierro de mayor antigüedad en el conjunto catedralicio, si bien las reformas que se realizaron para acondicionar la capilla al uso vigente han inducido a cuestionar su originalidad (Amenós 2004: 142) ${ }^{10}$.

\footnotetext{
10 La capilla acoge en la actualidad el sepulcro del banquero Manuel Girona Agrafel, patrocinador de las obras de finales del s. XIX e inicios del XX que afectaron la fachada, el cimborio y supusieron numerosas restauraciones internas en la basílica, en dependencias anexas y en el claustro, entre ellas algunas rejas de capilla, circunstancia que induciría a suponer la refacción completa del espacio destinado a la tumba del mecenas. En contraposición al supuesto anterior, existen diversos argumentos que confirman su originalidad: los enrejados contemporáneos contrastados se caracterizan por un recargado estilo neogótico flamígero, factura antagónica a la simplicidad de la reja 7; paradójicamente, el enrejado de la capilla que debía convertirse en panteón familiar mantiene la heráldica del anterior patrocinador medieval, sin que se halle referencia alguna al nuevo uso; la confirmación definitiva proviene de los resultados analíticos del presente estudio, que apuntan a una elaboración de origen preindustrial y diferenciada de los procedimientos de la siderurgia moderna.
} 


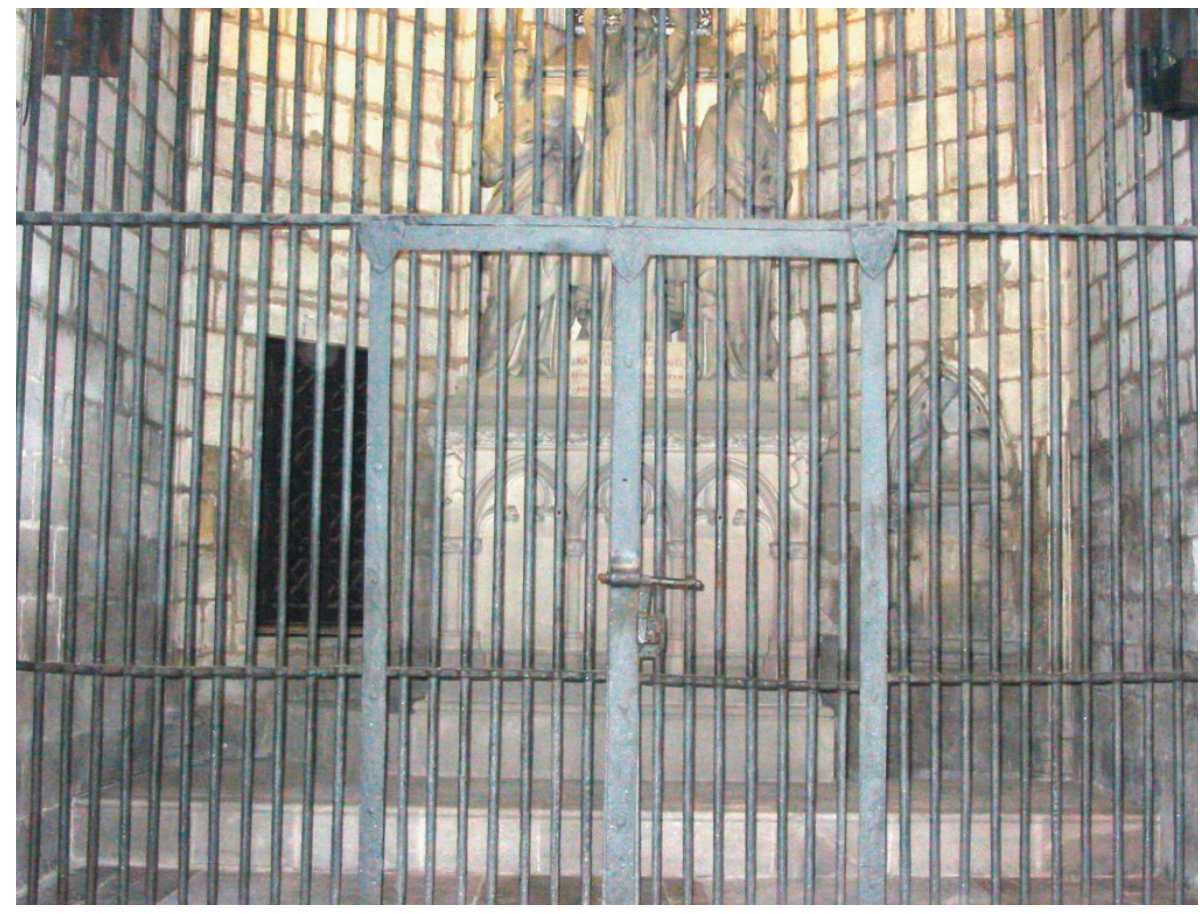

Figura 9. Imagen genérica del enrejado 7 (capilla del sepulcro de la familia Girona Agrafel).
Contrariamente a la mayor parte de las rejas estudiadas, ésta se caracteriza por la simplicidad y austeridad decorativa, circunstancia que destaca la ortogonalidad del conjunto, si bien el desgaste de las bisagras de uno de los batientes y la conservación deficiente desmerece su valor. De triple pasamanos, presenta una alta frecuencia de barrotes longitudinales que los atraviesan y que obligan a engrosar la sección a cada paso de elemento; dichos barrotes son de sección circular irregular, de factura tosca, en sintonía con la sencillez de la reja. Sin pasamanos a ras del pavimento, los barrotes y los bastidores encajan directamente en las losas pétreas del suelo mediante espigas con remaches de suspensión de elementos decorativos perdidos. E1 acceso es de doble batiente y muestra refuerzo de cubrimiento en los marcos, el umbral y en el bastidor central, creando la superficie donde se apoyaron los escudos con la heráldica del patrocinador inicial de la capilla. Siguiendo secuencias de cinco barrotes, la crestería está formada por flores o florones simples abiertos con punzón central.

\subsubsection{Muestra 0701}

Obtenida de un remache de sujeción de un elemento desaparecido y fijado en la parte inferior del bastidor. Elemento forjado en hierro o acero.

\section{Descripción del metal y estudio analítico}

Presenta una microestructura ferrítico-perlítica de muy bajo contenido en carbono (C) (104 HV) o ya ferrítica
(94,2 HV); en una zona perimetral, y de forma localizada y aleatoria, se advierte una área más carburada $(127,8$ $\mathrm{HV}$ ) (figura 10).

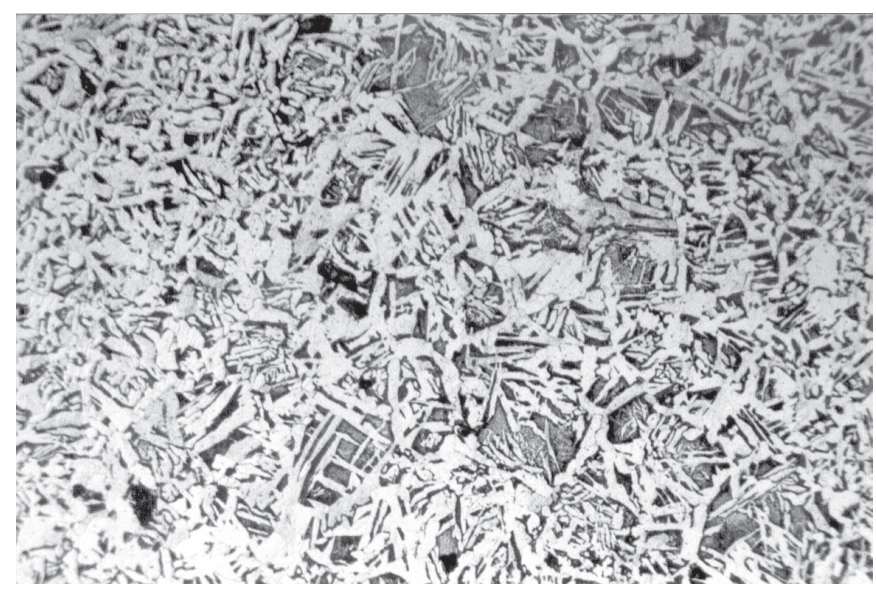

Figura 10. Fotomicrografía de la muestra 0701 con imagen de la microestructura ferríticoperlítica (x 440 augm.).

En general, la granulometría ferrítica se muestra poligonal, sin deformación visible, con tamaño homogéneo, pequeño o mediano; granos de perlita y algunas cadenas de cementita se ubican en los límites de los granos de ferrita. En referencia a la zona puntual de mayor carburación, se observa una microestructura ferrítico-perlítica $(0,4 \% \mathrm{C}$ aprox.) con disposición acicular tipo Widmanstätten de la granulometría ferrítica; 
en áreas más internas, se aprecia naturaleza laminar y globular en la perlita. Se ha realizado el análisis cualitativo de la matriz metálica comprobándose que los elementos hierro $(\mathrm{Fe}) \mathrm{y}$, en mínima proporción $\mathrm{C}$, componen el metal.

Son numerosas y diversas las inclusiones no metálicas y se distingue singularmente una tipología de dimensiones variables y forma irregular donde se observan fases internas. Las analíticas cualitativas identifican dichas fases: el espectro del fondo de la inclusión (figura 11) muestra un conjunto de elementos que se supone forman una fase cristalina con un silicato olivino-fayalítico $\left((\mathrm{FeMn})_{2} \mathrm{SiO}_{4}\right.$, tefroita); el resto de componentes advertido formaría un silico-aluminato probablemente vítreo; como en otras muestras estudiadas, destaca la presencia de trazas de fósforo (P) y azufre (S). La analítica de los nódulos de la inclusión (figura 12), de tonalidad más clara que el fondo, presenta los elementos hierro $(\mathrm{Fe})$, manganeso $(\mathrm{Mn})$ y oxígeno $\left(\mathrm{O}_{2}\right)$ que formarían un óxido de hierro-manganeso tipo wustítico; en proporción menor también aparecen los elementos calcio (Ca), silicio ( $\mathrm{Si}$ ) y aluminio (Al).

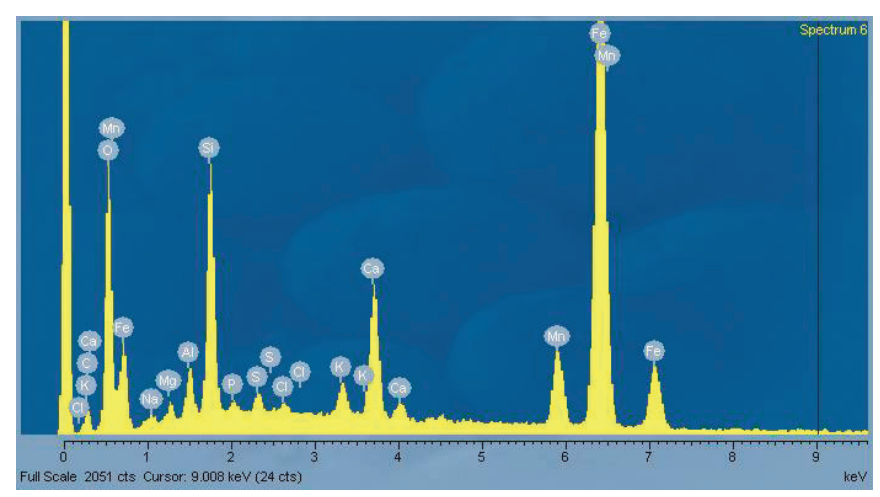

Figura 11. Análisis cualitativo del fondo o remanente de una inclusión no metálica de la muestra 0701.

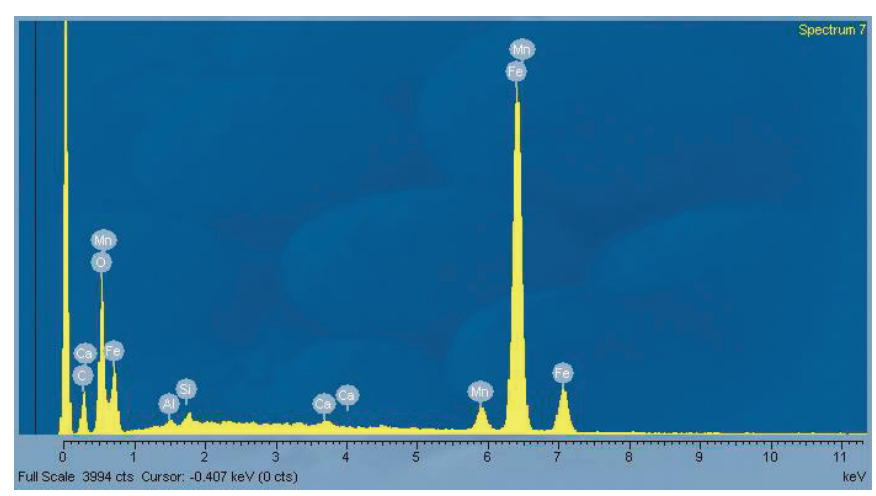

Figura 12. Análisis cualitativo de un nódulo correspondiente a la misma inclusión no metálica de la muestra 0701.

\section{Interpretación}

La muestra de estudio corresponde a un pequeño remache o roblón de sujeción, siendo la superficie analizada su sección íntegra. Se trata de hierro de la calidad estandarizada en la farga catalana conocida como "hierro bueno" (Molera y Barrueco 1983: 24), el más apto para trabajar en la forja debido su ductilidad y sin características específicas de dureza.

La zona de mayor carburación, con perlita y cadenas de cementita terciaria intergranular, puede ser interpretada como una cementación local, sin intencionalidad apreciable; una hipótesis alternativa consideraría la carburación como original de la esponja de metal tras la reducción. En todo caso, la disposición acicular de la granulometría indicaría que se produjo un enfriamiento relativamente rápido, posiblemente provocada por la temperatura ambiente en un contexto frío. La perlita laminar indica un enfriamiento al aire, posterior a un calentamiento (en el horno o la fragua) de austenización incompleta, lo que permitió la formación de la perlita globular también observada. Las estructuras aciculares, tipo Widmanstätten, son difíciles de destruir, incluso con recalentamientos posteriores.

El resto de la microestructura muestra un hierro químicamente puro, donde los límites de grano son poco visibles; el tamaño reducido de grano indica que no se superó significativamente y de forma mantenida la temperatura de austenización $\mathrm{Ac}_{3}$ (aprox. $900^{\circ} \mathrm{C}$ ); la granulometría tampoco muestra deformación, lo que señala que se trabajó en caliente, a temperatura suficiente para la restauración simultánea.

En referencia a las inclusiones complejas, éstas forman las fases típicas de las escorias del método directo, con nódulos formados por wustita, una fase cristalina fayalítica y un fondo de silicato actuando como remanente de los elementos minoritarios. Las tres fases mencionadas identificarían escorias de primera reducción, originarias del mineral, y mostrarían un proceso de depuración ineficiente. Tal y como se atestigua en otras muestras, la presencia de fósforo $(\mathrm{P})$ está vinculada al mineral original de hierro; el hallazgo de azufre (S) podría motivarse por una contaminación durante la forja del útil o por ser originarios del mineral. En el mismo sentido, y como en muestras precedentes, la presencia de potasio $(\mathrm{K})$ y calcio $(\mathrm{Ca})$ se relacionaría, respectivamente, al combustible utilizado, carbón vegetal, y a las reacciones químicas con el recubrimiento interior de la infraestructura durante la reducción. 


\section{DISCUSIÓN}

Uno de los aspectos de discusión que sugería el conjunto de rejas de estudio se centraba en su originalidad gótica. Esta cuestión se planteaba a partir de determinadas noticias documentales (Amenós 2004: 142-144) que aludían a actuaciones sobre algunos enrejados durante las restauraciones de finales del s. XIX y posteriores. En dicho sentido, es conocida y reproducida en tecnología siderúrgica contemporánea la capacidad de obtener acero de muy bajo contenido en carbono a partir del método indirecto (Guliáiev 1994: 198). Ante la incógnita respecto la real datación de las rejas analizadas, cabe argumentar los siguientes indicios:

- El metal estructural de las rejas es de gran pureza y corresponde a un hierro casi puro, sin otros elementos hallados a nivel analítico, o un acero con muy bajo porcentaje de carbono; en nomenclatura de la farga se identificaría como "hierro dulce" o "hierro bueno".

- Esta calidad de metal era conocida y utilizada para la confección de barrotes y rejas en época medieval, ya que confería al producto final una dureza relativa pero suficiente para sus necesidades mecánicas, alto límite elástico y una gran tenacidad, aparte de la conocida resistencia a la corrosión.

- Todas las muestras estudiadas, inclusive la documentalmente susceptible de ser de factura moderna, presentan numerosas inclusiones no metálicas con características propias del subproducto obtenido por el método directo.

- En el mismo ámbito de las rejas de la Catedral ${ }^{11}$ se analizó una muestra de un elemento sobreañadido a una reja original, una rejilla decorativa de arcuaciones apuntadas (Auladell y Simon 2012: 63-67). Microestructuralmente correspondía a una fundición gris (Guliáiev 1994: 202), donde el carbono se hallaba en estado libre y en forma de grafito laminar.

Las características comunes de las rejas históricamente identificadas como góticas reconocen un metal acorde con el producto de la farga; en contraposición, se ha podido detectar una evidencia de fundición que no reproduce las microestructuras de las estructuras precedentes. No existen razones para suponer que, en otros

11 En el presente artículo se han presentado los datos relativos a algunas muestras de determinadas rejas (enrejados 1, 2 y 7), quedando ajenas al mismo los resultados de las muestras de cuatro rejas más (enrejados 3, 4, 5 y 6). casos de substitución de rejas antiguas, se procediera de forma diferente.

Las rejas originarias muestran una especial resistencia a la corrosión y a la perdurabilidad, todavía vigente tras más de medio milenio. Por orden general, se considera que uno de los motivos que justifican la pervivencia de las estructuras de hierro se halla en la estructura fibrosa de la granulometría del metal, lo que no se evidencia en ninguna muestra del conjunto estudiado (Molera y Barrueco 1983: 80); al contrario, son características las microestructuras no deformadas, indicadoras de un trabajo mecánico a temperatura de recristalización, consiguiendo una continuidad del metal menos propensa a la fragilidad o la rotura. Entre otras razones ${ }^{12}$, el buen estado de conservación se debe a que el hierro obtenido por el método directo no alcanzaba temperaturas suficientes para incorporar otros elementos que pudieran ser perjudiciales ${ }^{13}$; esta pureza y la formación en proceso natural de magnetita (óxido ferroso-férrico, $\mathrm{Fe}_{2} \mathrm{O}_{3}$ ), de color negro adherente a la superficie y casi impenetrable para el aire atmosférico, protegían al metal (Molera y Barrueco 1983: 80).

Desde el campo de la arqueología experimental se han logrado reproducciones de los procesos del método catalán, descritos al detalle por tratados clásicos como el de J. M. Muthuon (1807) y el de J. François (1843). El producto resultante de la reducción muestra las mismas estructuras Widmanstätten, ya presentes en producciones de la siderurgia antigua, al parecer a causa de la práctica de presionar todo el material metálico del interior del horno con la pala y contra la masa incandescente para evitar las pérdidas de hierro; de las posteriores porciones de la masa de hierro-acero se procedía a elaborar los objetos trabajando al rojo en la fragua, pero a temperatura insuficiente para eliminar la microestructura acicular, reliquia de la reducción.

La necesidad de conformar piezas de gran tamaño, como pasamanos o barrotes, implicaba la soldadura de porciones de metal. La técnica también se empleaba con capas de diferente gradiente de carbono, lo que permitía aportar propiedades mecánicas específicas a remaches o clavos que debían soportar tensiones más elevadas; mediante el color y la resistencia al corte se identificaban en todo momento las zonas del metal de diferente carburación.

\footnotetext{
12 Aspectos ambientales vinculados a la contaminación atmosférica.

13 Los elementos intermedios, (Mn, Cr, V) precisan de temperaturas superiores a las alcanzadas habitualmente por la farga para aliarse con el metal, pasando a las inclusiones no metálicas.
} 
En referencia a las inclusiones presentes en el hierro y acero, se advierten las fases propias de las escorias de método directo: nódulos de wustita, una fase cristalina fayalítica y un fondo de silicato remanente de elementos minoritarios. Las tres fases corresponden a restos del subproducto de primera reducción, identificadoras del mineral y testimonio de una reducción incapaz de licuar la totalidad de escoria y de una post-reducción incompleta. A nivel analítico, se ha reconocido manganeso en todas las muestras, elemento no extraño en los filones de mineral de hierro y habitual del Pirineo, Cataluña norte y el prelitoral central ${ }^{14}$, origen concordante con las noticias históricas respecto los talleres productores (Simon 1992; 20-32; Auladell 2005: 52-57). Dicho elemento se halla habitualmente en las inclusiones, circunstancia indicadora de hornos de reducción a temperaturas inferiores al tránsito del manganeso a la matriz metálica (1245 ${ }^{\circ} \mathrm{C}$ aprox.). También se ha identificado azufre en alguna de las inclusiones de las muestras, indeseable en la matriz metálica ya que la fragiliza, pero que no afecta si se ubica en las inclusiones como es el caso. No hay certeza sobre su procedencia, quizá contaminación del horno, traza del mineral, como el fósforo, de un uso desconocido o limitado de carbón de origen mineral, o, más factiblemente, vinculado al combustible vegetal, ya que el elemento está presente en pequeña proporción en el pino mediterráneo. El potasio podría relacionarse al carbón vegetal y el calcio sería el testimonio de un horno de reducción de factura primitiva, sin interior forrado, que permitía la transferencia durante la reducción.

En relación a las aleaciones de cobre analizadas, motivos decorativos y molduras, el tamaño del detalle ornamental obligaba a un minucioso trabajo del metal, por lo que se recurría a la técnica del moldeo. Sin necesidad de dureza, la moldeabilidad, especialmente en los adornos vegetales y florales, se convertía en el requerimiento mecánico fundamental.

Existen diferencias notables en el metal base cobre empleado. Por una parte se encuentra bronce, cobre y estaño en proporciones diversas de aleación, utilizado básicamente para las molduras a las que confieren color rojizo oscuro; por otro, se detecta el uso del latón, cobre y zinc, dedicado a las decoraciones vegetales, a las que dota de un color dorado brillante y claro. Es posible un uso de materiales amortizados mezclando objetos de composición diferente que provoca muestras de bronce-latón y de

\footnotetext{
14 Auladell, J. 2005: Tecnologia del treball del ferro al nordest peninsular en l'ibèric antic i ple, Tesis Doctoral, Universitat de Barcelona.
}

aleación $\mathrm{Cu}-\mathrm{Sn}-\mathrm{Zn}-\mathrm{Pb}$. La presencia de plomo resultaba contraproducente por su mayor capacidad de deformación pero facilitaba el moldeo.

De la práctica antigua se constata la acumulación de recortes de cobre para su fundición, por lo que no extraña la inclusión conjunta de fragmentos de bronce y latón ${ }^{15}$. En el ornamento floral (muestra 0203) el zinc sólo está presente en las inclusiones de azufre y éstas se encuentran en poca cantidad; sin presencia en los espectros de la fase metálica interdendrítica, se puede hipotetizar acerca de un proceso de desintegración del zinc producido por la corrosión atmosférica, con supuesto alto índice de azufre ambiental.

\section{CONCLUSIONES}

El interés de las estructuras metálicas estudiadas responde a su sincronía con las fases iniciales de la construcción del templo gótico (siglos XIV-XVI). Esta etapa en la tecnología siderúrgica supone un momento intermedio en la evolución del método catalán; con energía hidráulica para fuelles y martinete y mayor temperatura del horno se logra un procedimiento más eficiente y un metal más depurado, pero todavía no se ha alcanzado un total dominio de las condiciones que afectan a la esponja metálica durante la reducción y que influyen en la homogeneidad del producto. En este sentido, uno de los aspectos principales que determinan el nivel tecnológico de los hierros medievales reside en el control de la carburación en el horno bajo, donde una misma infraestructura permite obtener indiferentemente hierro o acero, en dependencia de la ventilación que convierte la masa en un producto con distribución aleatoria de carbono; el flujo de aire se erige en el parámetro esencial: posición, inclinación y orientación de las toberas, cantidad de aire inyectado y regularidad de alimentación (Forrieres y Merluzo 1995: 84-86). La evolución técnica posterior al conjunto muestral solucionó el problema con la incorporación de la trompa de aire que proporcionaba continuidad al flujo de ventilación y, por tanto, daba uniformidad a las condiciones del producto de la reducción a voluntad del metalúrgico (Simon 1992: 64-65).

Con las características previas evidenciadas en las muestra de estudio se forjaron barrotes, pasamanos y elementos de sujeción de hierro y acero de baja carburación.

\footnotetext{
15 Anteriormente para producir latón se añadía carbonato de zinc nativo, el zinc no se aisló hasta el siglo XVIII, en forma de calamina al cobre fundido.
} 
A partir de una calidad estandarizada de hierro casi puro, los enrejados se conformaron con las técnicas necesarias para asegurar una larga perdurabilidad, siendo a su vez eficaces en la función estructural encomendada y consiguiendo un cromatismo que, del brillo metálico original, tendía a oscurecerse con una pátina de óxido protector natural. En un plano más pragmático, se localizó la totalidad de la cadena logística (obtención de la materia prima, transformación y obra final) en un contexto de proximidad, posibilitando la máxima eficiencia productiva y de costes. Complementando al hierro y al acero se utilizaron las aleaciones de cobre para elaborar los elementos decorativos que, a la solidez del conjunto y al estilismo artístico, añadían un sobrio grado de ostentación y combinación cromática. Nuevamente, los artesanos muestran practicidad en el uso de material reciclado muy diverso, alternando bronces y latones para conseguir elementos de composición heterogénea, más duras las molduras y más moldeables las decoraciones, que permitían una detallada elaboración y un atractivo impacto visual.

\section{AGRADECIMIENTOS}

El presente artículo se enmarca en el proyecto interuniversitario "Convenio sobre el estudio tecnológico y estructural de los objetos de hierro protohistóricos e históricos del nordeste peninsular", vigente hasta 2012 entre los grupos de investigación GRAP (UB) y PROCOMAME (UPC), llevado a cabo por los investigadores Dr. Jordi Auladell y Dra. Júlia Simon. Los autores desean agradecer el apoyo incondicional del Dr. José Manuel Prado Pozuelo (CTM, UPC) y la colaboración inestimable del Sr. Isaac López-Insa (CMEM, UPC).

La Dra. Júlia Simon Arias, coinvestigadora del proyecto, falleció durante la redacción del artículo; su discípulo y coautor manifiesta el perenne agradecimiento a la maestra y amiga.

\section{BIBLIOGRAFIA}

ASM International Handbook Committee, 1990: ASM Handbook Volume 02. Properties and Selection: Nonferrous Alloys and Special-Purpose Materials, ASM Intern. Publisher.

Auladell, J. y Simon, J. 1997: “Anàlisi metalogràfica d'elements fèrrics preromans: una aproximació als mètodes siderúrgics a la Laietània", Pyrenae, 28, pp. 119-132.

Fluzin, P. 1994: "Interprétation des études métallographiques des scories. Recherche d'éléments discriminatoires", La sidérurgie ancienne de l'Est de la France dans son contexte européen (Actes du Colloque de Besançon, 10-13/11/1993), pp. 24-30, Annales littéraires de l'Université de Besançon. Université de Besançon, Paris.

Forrieres, C. y Merluzo, P. 1995: "Les premieres étapes du travail du fer en foyer de forge, selon des procédés traditionnels japonais", en P. Benoit y P. Fluzin (coord.), Paleometallurgie du fer \& Cultures, pp. 71-86. Vulcain, Paris.

François, J. 1843: Le gisement et le traitement direct des minerais de fer dans les Pyrénées et particulierèment dans l'Ariège. Carilian-Goeury et V. Dalmont, Paris.

Gil, F. J. y Manero, J. M. 2005: Metalografia. Universidad Politécnica de Catalunya, Barcelona.

Guliáiev, A. P. 1994: Metalografia (tomo 1). URSS, Moscú.

Martí, J. M. 2003: Oleguer, servent de les esglésies de Barcelona i Tarragona. Arxiu Diocesà de Barcelona. Editorial Claret. Barcelona

Mas, C. 2000: Història de la farga catalana. Pagès, Barcelona.

Mascarella, J. 1993: La farga, Quaderns de la revista de Girona. Dip.de Girona, Girona.

Molera, P. 1991: Tratamientos térmicos de los metales. Marcombo Boixareu Editores, Barcelona.

Molera, P. y Barrueco, C. 1983: Llibre de la Farga. Rafael Dalmau, Barcelona.

Muthuon, J. M. 1807: Traité des forges dites catalanes. Manucius, Paris.

Seernels, V. 1998: "La chaîne opératoire de la sidérurgie ancienne", en M. Feugère y V. Serneels (dir.), Recherches sur l'économie du fer en Mediterranée nord-occidentale, Monographies Instrumentum, 4, pp. 7-44. Monique Mergoil, Montagnac.

Simon, J. 1992: La farga catalana, Monografies de Tecnologia 1. Societat Catalana de Tecnologia, Barcelona.

Simon, J., Auladell, J. y Prado, J. M. 1997: “Aproximación a las propiedades mecánicas de los útiles de hierro prerromanos en la Layetania (MontjuïcBarcelona)", en Actas del V Congreso Nacional sobre Propiedades Mecánicas de los sólidos (Barcelona, 3-5/7/1996), pp. 372-377. Universidad Politécnica de Catalunya, Barcelona.

Simon, J., Tartera, J., Marsal, M. y Auladell, J. 2003 "De los Íberos al Imperio Romano. Evolución tecnológica del hierro", en Actas del IX Congreso de ciencia y tecnología metalúrgicas (Madrid, 5-7/11/2003), pp. 115-132. Publicaciones del Centro Nacional de Investigaciones Metalúrgicas, Madrid. 